\title{
Edward Lee-Six, «Je fixais des vertiges» Les étourdissements du «Bateau ivre» de Rimbaud
}

\section{Maria Emanuela Raffi}

\section{(2) OpenEdition}

1 Journals

\section{Edizione digitale}

URL: http://journals.openedition.org/studifrancesi/1582

DOI: 10.4000/studifrancesi. 1582

ISSN: 2421-5856

Editore

Rosenberg \& Sellier

\section{Edizione cartacea}

Data di pubblicazione: 1 novembre 2014

Paginazione: 624

ISSN: 0039-2944

\section{Notizia bibliografica digitale}

Maria Emanuela Raffi, «Edward Lee-Six, «Je fixais des vertiges» Les étourdissements du «Bateau ivre» de Rimbaud », Studi Francesi [Online], 174 (LVIII | III) | 2014, online dal 01 novembre 2014, consultato il 18 septembre 2020. URL : http://journals.openedition.org/studifrancesi/1582 ; DOI : https://doi.org/ 10.4000/studifrancesi. 1582

Questo documento è stato generato automaticamente il 18 settembre 2020.

\section{(c)}

Studi Francesi è distribuita con Licenza Creative Commons Attribuzione - Non commerciale - Non opere derivate 4.0 Internazionale. 


\title{
Edward Lee-Six, «Je fixais des vertiges» Les étourdissements du «Bateau ivre» de Rimbaud
}

\author{
Maria Emanuela Raffi
}

\section{NOTIZIA}

EDWARD LEE-SIX, «Je fixais des vertiges» Les étourdissements du «Bateau ivre» de Rimbaud, «French Forum», n. 38, 3, 2013, pp. 49-64.

1 Su che scala di considerazioni e di relazioni si collochi questa lettura del «Bateau ivre» di Rimbaud appare chiaro già scorrendo la singolare bibliografia che la accompagna, che va da Baudelaire a Dante, da Barthes a Beckett a Blake, da Coppée a Eliot, da Omero a Hugo, da Poe a Sofocle e da Verlaine a Virgilio. Nella prospettiva ampiamente diacronica di Edward Lee-Six, lo stesso Guyaux, citato nella prima riga dell'articolo, sparisce nella bibliografia, mentre non c'è traccia nello studio delle sessanta dense pagine dedicate alla poesia rimbaudiana da Steve Murphy (Logiques du "Bateau ivre", " Littératures», 2006), né di quelle, numerose, consacrate alla sua metrica da Benoît de Cornulier. L'A. sceglie infatti di affrontare la «lexicographie dédalienne» del «Bateau ivre» prendendo come guida uno studio di A.-R. Chisholm del 1930. L'interesse della proposta di Lee-Six sta tutto nelle numerose comparazioni che propone, in parte con opere classiche come l'Iliade, l'Eneide o il Purgatorio dantesco, sia pure spesso attraverso il fragile confronto di singoli versi, in parte con opere moderne come Vingt mille lieues sous les mers, L'Après-midi d'un Faune e soprattutto Les Travailleurs de la mer di Victor Hugo, di cui l'A. prende sorprendentemente in esame l'edizione in bande dessinée per mostrare «le curieux mariage [realizzato da Rimbaud] de ce qui appartient au monde des histoires d'aventures [...] et la conscience du caractère sombre de ces mêmes fantaisies de l'autre». Di certo questo articolo attesta l'estrema vitalità e l'attrazione del 
testo rimbaudiano, che, pur resistendo, offre ad ogni tipo di lettura qualche spiraglio di riflessione sull'infinito ventaglio delle sue interpretazioni. 